\title{
PENGARUH RIWAYAT INFEKSI DAN ASI EKSKLUSIF TERHADAP TUMBUH KEMBANG BALITA DALAM MENCEGAH STUNTING
}

\author{
Elfalini Warnelis ${ }^{1}$, Debora Simamora ${ }^{2}$ \\ ${ }^{1,2}$ Universitas Imelda Medan \\ geoffreygopaz@gmail.com, hilbramgavriel@gmail.com
}

\begin{abstract}
Stunting is a condition where the toddler's height is less than normal, this is an important problem for Indonesia today. The research method used naturalistic phenomenology with a retrosfective study approach. location in the Kelurahan Pekan Labuhan Medan., a total sample of 50 people, questionnaire interview research instruments. The results showed that there was an effect of infection history and exclusive breastfeeding on toddler growth and development. The results of the statistical analysis of the T test showed that the history of infection had an influence on the growth and development of children under five ( $p=0.01 ; p<0.05)$, exclusive breastfeeding had an effect ( $p=0.02 ; p<0.05)$ on the growth and development of children under five. Suggestions for further research with a different design.
\end{abstract}

Keywords : History of infection; exclusive breastfeeding; Growth and development

\section{PENDAHULUAN}

Prevalensi stunting di Indonesia cenderung statis. Pada tahun 2010, terjadi sedikit penurunan dari tahun sebelumnya yaitu $35,6 \%$. Namun prevalensi balita pendek kembali meningkat pada tahun 2013 yaitu menjadi 37,2\%. Hasil Badan Pusat Statitik 2018 menunjukkan prevalensi balita pendek di Indonesia sebesar 19,3\% dan balita sangat pendek $11,5 \%$. (BAPPENAS \& UNICEF, 2017).

Penyakit infeksi yang disebabkan oleh hygiene dan sanitasi yang buruk (misalnya diare dan kecacingan) dapat mengganggu penyerapan nutrisi dan proses pencernaan. Beberapa penyakit infeksi yang diderita baik dapat menyebabkan berat badan bayi turun. Jika kondisi ini terjadi dalam waktu yang cukup lama dan tidak disertai dengan pemberian asupan yang cukup untuk proses penyembuhan maka dapat mengakibatkan stunting. (Teja, 2019)

Faktor nutrisi yang

diperolehsejak bayi lahir sangat berpengaruh terhadap pertumbuhannya termasuk risiko terjadinya stunting. Salah satu penyebab terjadinya stunting adalah, tidak terlaksananya inisiasi menyusu dini (IMD), gagalnya pemberian air susu ibu (ASI) eksklusif, dan proses penyapihan dini. (Sebayang W, 2017) Sedangkan 
dari sisi pemberian makanan pendamping ASI (MP ASI) hal

yang perlu diperhatikan adalah

kuantitas, kualitas, dan keamanan

pangan yang diberikan. (Lestiarini

\& Sulistyorini, 2020)

Pemberian ASI bagi bayi baru

lahir merupakan salah satu upaya untuk mencegah kematian dan masalah kekurangan gizi pada bayi dan balita.

World Health Organization (WHO 2010) merekomendasikan agar bayi baru lahir diberikan ASI hingga usia 6 bulan tanpa memberikan makanan atau cairan lain, kecuali vitamin, mineral, dan obat yang telah di ijinkan karena adanya alasan medis. Sesudah 6 bulan bayi baru dapat diberikan makanan tambahan pendamping ASI dengan tetap memberikan ASI sampai umur 2 tahun. (Hartanti, 2014)

Menurut UNICEF, cakupan rata-rata ASI eksklusif di dunia yaitu 38\%. Cakupan ASI Eksklusif di Indonesia (54,3\%). Cakupan pemberian ASI eksklusif di Indonesia tahun 2017 sebesar 55, $96 \%$, angka menunjukkan bahwa masih cukup banyak bayi yang belum mendapatkan ASI eksklusif.

(BAPPENAS \& UNICEF, 2017)

Anak yang mendapatkan ASI sejak dini umumnya mengalami perkembangan dengan cepat dibandingkan dengan anak yang hanya mendapatkan susu formula, anak yang hanya mendapat susu formula cenderung mengalami perkembangan yang kurang atau terlambat dan ini akan mempengaruhi kualitas tumbuh kembang anak. (Fitri et al., 2014). Melalui penelitian ini diharapkan menghasilkan sebuah pembaharuan kebijakan baik petugas kesehatan maupun keluarga mandiri untuk lebih optimal dalam meningkatkan kualitas tumbuh kembang balita demi generasi penerus bangsa.

\section{METODE}

Penelitian ini menggunakan rancangan Fenomenologis

naturalistik dengan pendekatan Retrosfektif study cross sectional. (Arikunto, 2010) Lokasi penelitian ini dilaksanakan di Kelurahan Pekan Labuhan Medan. Populasi penelitian ini adalah seluruh ibu - ibu yang mempunyai anak usia 6 bulan sampai 5 tahun. Tehnik pengambilan sampel dengan metode acidental sampel, dengan jumlah sampel 50 orang. Variabel bebas dalam penelitian ini adalah Riwayat infeksi dan riwayat pemberian Asi eksklusif. 


\section{HASIL DAN PEMBAHASAN}

Perkembangan Anak Balita

Tabel 1. Distribusi Perkembangan Anak Balita

\begin{tabular}{lcc}
\hline \multicolumn{1}{c}{ Perkembangan } & Jumlah & Persentase \\
\hline Sesuai & 41 & 82 \\
Meragukan & 9 & 18 \\
Jumlah & $\mathbf{5 0}$ & $\mathbf{1 0 0}$ \\
\hline
\end{tabular}

Sumber : Data Primer Tahun 2020

Berdasarkan hasil diatas dapat orang tua dalam memaksimalkan dilihat bahwa ditemukan $18 \%$ jumlah tumbuh kembang Balita. Untuk Balita dengan perkembangan yang meningkatkan pengetahuan ibu - ibu meragukan. (Kedokteran Unhas, 2018) yang mempunyai Balita salah satu upaya Data dari hasil penelitian ini menjadi perhatian khusus mengingat perkembangan Balita akan mempengaruhi kualitas generasi penerus bangsa pada masa yang akan datang. Oleh karena itu sesuai dengan penatalaksanaan perkembangan yang bisa dilakukan adalah dengan membuat kelas ibu balita dalam meningkatkankan ketrampilan stimulasi tumbuh kembang. Proses belajar dari pengalaman peserta dan fasilitator terbukti efektif meningkatkan pengetahuan dan ketrampilan tentang meragukan maka perlu dilakukan tumbuh kembang Balita (Ina Handayani, stimulasi rangsangan dan peran serta

\section{Riwayat Infeksi}

Tabel 2. Distribusi Frekuensi Riwayat Infeksi

\begin{tabular}{lcc}
\hline \multicolumn{1}{c}{ Riwayat Infeksi } & Jumlah & Persentase \\
\hline Berisiko & 14 & 28 \\
Tidak Berisiko & 36 & 72 \\
\hline Jumlah & $\mathbf{5 0}$ & $\mathbf{1 0 0}$ \\
\hline
\end{tabular}

Hasil penelitian didapat bahwa jumlah balita dengan riwayat infeksi kategori berisiko cukup besar yaitu 28 $\%$. Kategori riwayat infeksi berisiko yang dimaksud disini adalah jumlah balita yang pernah mengalami sakit sampai opname rawat nginap dan mendapat therapy antibiotic injeksi selama masa perawatan. 


\section{Riwayat ASI Eksklusif}

Tabel 3. Distribusi frekuensi pemberian ASI Eksklusif

\begin{tabular}{lcc}
\hline \multicolumn{1}{c}{ Riwayat Infeksi } & Jumlah & Persentase \\
\hline ASI ekslusif & 17 & 34 \\
Tidak ASI Eksklusif & 33 & 66 \\
Jumlah & $\mathbf{5 0}$ & $\mathbf{1 0 0}$
\end{tabular}

Sumber : Data Primer tahun 2020

Hasil penelitian menunjukkan jumlah persentasi responden yang memperoleh ASI ekslusif masih rendah yakni hanya sebesar $34 \%$. Persentase ASI Ekslusif ini masih jauh harapan. Banyak penelitian telah membuktikan bahwa ASI Eksklusif adalah yang terbaik untuk pertumbuhan dan perkembangan anak, namun masih banyak masyarakat yang belum menyadari sehingga keberhasilan ASI ekslusif belum maksimal.(Aziezah Nur, 2011) Pengetahuan tentang manfaat, keuntungan dan pentingnya ASI eksklusif masih merupkan penyebab kegagalan efektifitas dari program ASI eksklusif di Indonesia, disamping itu pendidikan dan pekerjaan ibu juga mempengaruhi ibu dalam memberikan ASI Ekslusif (Sihombing, 2018) (Perpustakaan, n.d.)

\section{Pengaruh Riwayat Infeksi Terhadap Tumbuh Kembang}

Tabel 4. Pengaruh Riwayat Infeksi Terhadap Tumbuh Kembang

\begin{tabular}{|c|c|c|c|c|c|c|c|}
\hline \multirow[t]{2}{*}{ Riwayat Infeksi } & \multicolumn{2}{|c|}{ Sesuai } & \multicolumn{2}{|c|}{ Meragukan } & \multicolumn{2}{|c|}{ Total } & \multirow[t]{2}{*}{$P$} \\
\hline & $\bar{n}$ & $\%$ & $\bar{n}$ & $\%$ & $\mathbf{N}$ & $\%$ & \\
\hline Berisiko & 5 & 36 & 9 & 64 & 14 & 100 & 0,01 \\
\hline Tidak berisiko & 36 & 100 & 0 & 0 & 36 & 100 & \\
\hline
\end{tabular}

Sumber : Data Primer tahun 2020

Tabel 4 diatas menunjukkan bahwa perkembangan meragukan sebagian besar terjadi pada anak yang memilikin riwayat infeksi berisiko dengan jumlah 9 (64\%). Jumlah anak yang tidak memiliki riwayat infeksi berisiko $100 \%$ dengan perkembangan kategori sesuai. Hasil statistic diperoleh p.value 0.01 yang berarti ada pengaruh yang signifikan riwayat infeksi terhadap
Tumbuh kembang Balita. Penelitian sebelumnya pada 97 anak Balita diwilayah kerja Puskesmas Tuminting Manado menyatakan tidak ada hubungan yang bermakna antara riwayat infeksi dengan kejadian stunting, namun demikian frekuensi anak dengan riwayat infeksi lebih besar mengalami stunting dibandingkan anak tanpa riwayat infeksi. (Gerungan et al., 2013) . 
Tabel 5. Pengaruh Pemberian ASI Terhadap Tumbuh Kembang

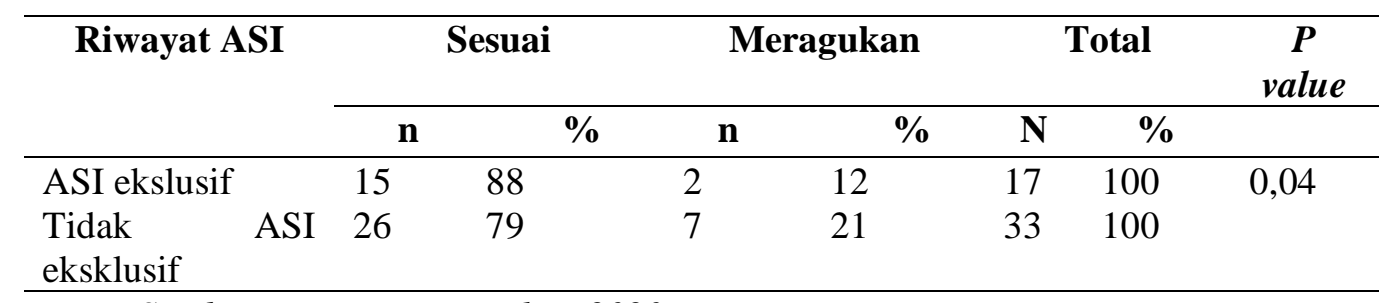

Sumber : Data Primer tahun 2020

Tabel 5 diatas menunjukkan bahwa anak yang memperoleh ASI eksklusif sebanyak 15 orang (88\%) dengan kategori tumbah kembang sesuai. Hasil statistic diperoleh p.value 0.04 yang berarti ada pengaruh yang signifikan pemberian ASI eksklusif terhadap Tumbuh kembang Balita. Penelitian ini sama dengan penelitian (Hartanti, 2014) yang menyatakan bahwa ASI eksklusif mempengaruhi gizi seorang anak, sehingga dapat beruhubungan dengan tumbuh kembang anak dan system immune anak dalam melawan infeksi. Hasil Riskesda tentang ASI eksklusif tahun 2012 telah mengalami kenaikan yaitu $32 \%$ tahun 2007 menjadi $42 \%$ (Kementerian Kesehatan RI \& MCA Indonesia, 2015). Penelitian case control terhadap 144 responden di Kecamatan Buntu Malangka Kabupataen Mamasa Makasar diperoleh hasil Balita yang tidak mendapat ASI eksklusif berpeluang mengalami Stunting $61 \quad$ kali dibandingkan bayi yang mendapat ASI ekslusif .(Latifah et al., 2020)

\section{KESIMPULAN DAN SARAN}

Setelah dilakukan uji statistik melalui uji chi square didapat bahwa p.value $(<0,05)$ yang berarti ada pengaruh riwayat infeksi dan pemberian ASI Eksklusif terhadap tumbuh kembang Balita dalam mencegah stunting.

Penelitian selanjutnya tentang asi eksklusif, riwayat infeksi dan stunting serta edukasi dan pelatihan dan kelas untuk ibu balita dalam meningkatkan stimulasi ketrampilan pemantauan tumbuh kembang.

\section{DAFTAR PUSTAKA}

Arikunto. (2010). Prosedur Penelitian Suatu pendekatan Praktik (Revisi). Rineka Cipta.

Aziezah Nur. (2011). Perbedaaan tingkat konsumsi dan status gizi antara bayi dengan ASI ekslusif dan non ASI eksklusif. $A D L N$ Perpustakaan Universitas

Airlangga.

BAPPENAS, \& UNICEF. (2017). Laporan Baseline SDG tentang Anak-Anak di Indonesia. Kementerian Perencanaan 
Pembangunan

Nasional

(Bappenas) Dan United Nations

Children's Fund, 1-105. https://www.unicef.org/indonesia/i d/SDG_Baseline_report.pdf

Fitri, D. I., Chundrayetti, E., \& Semiarty, R. (2014). Hubungan Pemberian ASI dengan Tumbuh Kembang Bayi Umur 6 Bulan di Puskesmas Nanggalo. Jurnal Kesehatan Andalas, 3(2), 136-140. https://doi.org/10.25077/jka.v3i2.5 1

Gerungan, G. P., Malonda, N. S. ., \& Rombot, D. V. (2013). Hubungan Antara Riwayat Penyakit Infeksi dengan Kejadian Stunting pada Anak Usia 13-36 bulan di Wilayah Kerja Puskesmas Tuminting Kota Manado. Jurnal Penyakit Infeksi Dan Stunting, 392, 0-5.

Hartanti, S. (2014). Hubungan Tingkat Pendidikan Ibu Dengan Keberhasilan ASI Eksklusif Pada Bayi Umur 6-12 Bulam di Puskesmas Kasihan Yogyakarta. Stikkes 'Aisyiyah, 1-19.

Ina Handayani, G. P. (2020). Jurnal Kesehatan Prima. Jurnal Kesehatan Prima, 14(1), 31-39. https://doi.org/10.32.807/jkp.v14i1 .254

Kedokteran Unhas. (2018). Buku panduan kuesioner pra skrining perkembangan (KPSP). Buku
Panduan Kuesioner Pra Skrining

Perkembangan (Kpsp), 1-25.

Kementerian Kesehatan RI, \& MCA Indonesia. (2015). Infodatin-Asi .Pdf. In Millennium Challenge Account - Indonesia (pp. 1-2).

Latifah, A. M., Purwanti, L. E., \& Sukamto, F. I. (2020). Hubungan Pemberian Asi Eksklusif Dengan Kejadian Stunting Pada Balita 1-5 Tahun. Health Sciences Journal, $4(1)$, 142. https://doi.org/10.24269/hsj.v4i1.4 09

Lestiarini, S., \& Sulistyorini, Y. (2020). Perilaku Ibu pada Pemberian Makanan Pendamping ASI (MPASI) di Kelurahan Pegirian. Jurnal PROMKES, 8(1), 1. https://doi.org/10.20473/jpk.v8.i1.

2020.1-11

Perpustakaan, A. (n.d.). PERBEDAAN TINGKAT KONSUMSI DAN STATUS GIZI.

Sebayang W. (2017). No TitlManfaat Massase Tengkuk dan Kompres Hangat Payudara Terhadap Pengeluaran Kolostrum ASI pada Ibu Postpartum di Klinik Pratama Rosni Alizar Medan Tahun 2017. Jurnal Ilmiah Kebidanan Imelda, 3(2), 267-270.

Sihombing, S. (2018). Hubungan Pekerjaan Dan Pendidikan Ibu Dengan Pemberian Asi Ekslusif Di 
Wilayah Kerja Puskesmas Hinai

Kiri Tahun 2017. Midwifery

Journal, 5(01), 40-45.

Teja, M. (2019). Stunting Balita Indonesia Dan

Penanggulangannya. Pusat

Penelitian Badan Keahlian DPR

RI, XI(22), 13-18. 